\title{
QUESTÃO ÉTNICO-RACIAL NA GEOGRAFIA BRASILEIRA: UM DEBATE INTRODUTÓRIO SOBRE A PRODUÇÃO ACADÊMICA NAS PÓS-GRADUAÇÕES'
}

\author{
Ethnic-racial issue in brazilian geography: \\ an introductiory debate about the academic \\ production in the post-graduations in geography \\ La question étnico-racial en la geografía brasileña: \\ un debate introductorio acerca de la produción \\ académica en los posgrados
}

\section{Diogo Marçal Cirqueira \\ Diogo Marçal Cirqueira - Doutor em Geografia pela Universidade Federal Fluminense (UFF). E-mail: Diogogeo@hotmail.com}

\section{Gabriel Siqueira Corrêa}

Gabriel Siqueira Corrêa - Doutorando em Geografia pela Universidade Federal Fluminense (UFF). Professor Assistente vinculado ao Departamento de Geografia da FFP/UERJ. E-mail: gabrielgeo@hotmail.com.br

\begin{abstract}
Resumo
O debate referente à questão étnico-racial, muito influenciado pelo movimento negro, se dinamiza nos últimos anos no Brasil. Há diante disso uma intensificação das pesquisas na academia, buscando compreender essa problemática que, por sinal, envolve a Geografia institucional. Assim, este artigo consiste no levantamento e análise das dissertações e teses produzidas nos programas de Pós-graduações em Geografia no Brasil até o ano de 2012, sobre a questão étnico-racial, em especial sobre a população negra. Com isso, pretende-se compreender como a Geografia acadêmica se insere nesse debate. Foram levantados ao todo cinquenta e quatro (54) trabalhos, dentre teses (13) e dissertações (41). Entre esses trabalhos, estabelecemos quatro tendências teóricometodológicas de abordagem acerca do tema. São elas: Espaço e relações étnico-raciais; identidades e territorialidades negras; geopolítica dos países africanos; e, território e lugar nas manifestações culturais negras.
\end{abstract}

Palavras-chave: Geografia, pós-graduação, relações étnico-raciais.

Agradecemos encarecidamente as críticas e sugestões realizadas pelos professores Dr. Adrelino de Oliveira Campos e Dr. Denilson Araújo de Oliveira, bem como, os profícuos comentários dos pareceristas anônimos da Revista. Também agradecemos a competente revisão realizada pela profa. Carlianne Paiva Gonçalves. Uma versão preliminar desse artigo foi apresentada no XII Colóquio Internacional de Geocrítica, realizado em Bogotá entre os dias 7 e 11 de maio de 2012. 


\begin{abstract}
Influenced by the black movement, the debate concerning ethnic-racial issues has become dynamic in recent years in Brazil. Consequently, it is possible to see an increase in research in different areas of study in Brazilian Universities, including institutional geography. This article aims to catalog and analyse dissertations and theses about the ethnic-racial relations, especially in the black population, which were produced in Graduate Geography programs in Brazil. We studied fifty four (54) research works, thirteen (13) of which were doctoral theses and fourty one (41) of which were master's dissertations. We also established four categories on the subject's theoreticalmethodological approaches. They are: Space and ethnic-racial relations; black identity and territoriality; geopolitics of African countries; and territory and place in black cultural manifestations.
\end{abstract}

Keywords: Geography, graduation, ethnic-racial relations

\title{
Resumen
}

El debate acerca de la cuestión étnico-racial, muy influido por el movimiento negro, se amplía en los últimos años en Brasil. Hay una intensificación tanbien en las universidades que intentan a comprender el problema en el país. Así, este estudio consiste en el levantamiento y el analisis de disertaciones y tesis acerca de la cuestión étnico-racial producidas en los programas de Posgrado en el Geografía de Brasil. Hemos recaudado un total de cincuenta y cuatro (54) obras, entre las tesis (13) y disertaciones (41). Entre este cuantitativo, fue definido cuatro tendencias teórico-metodológico sobre el tema. Ellos son: El espacio y las relaciones étnico-raciales; la identidad y territorialidad negro; la geopolítica de los países africanos; y el territorio y el lugar de las manifestaciones culturales negras.

Palabras-clave: Geografía, posgrado, relaciones étnico-raciales 


\section{INTRODUÇÃO}

Sem dúvida, quando se procura analisar os fatores que compõem a formação da "nação brasileira", a questão étnico-racial é um dos assuntos mais importantes, bem como, um dos mais polêmicos. Ao observar a literatura que analisa esse tema, notamos que as discussões vigoram desde o século XIX, marcadas profundamente por interesses políticos e ideológicos (cf. SEYFERTH, 1996; SKIDMORE, 1976; SCHWARCZ, 1993). Constituindo-se, assim, como um tema delicado e complexo, nunca houve consenso em torno das teorias que buscaram responder "quem é o povo brasileiro?”, consequentemente, “o que faz do Brasil, Brasil?”. Um pensamento comum, talvez, seja que toda problemática que compõe a questão étnico-racial gire em torno da ideia de miscigenação. Mesmo assim, as respostas mais conhecidas a respeito dos questionamentos acima que buscaram definir a identidade e a nação brasileira, movimentando por dentro da ideia de miscigenação, ou afirmam que aqui vivenciamos um "paraíso racial", produto da mistura entre três raças (europeus, africanos e indígenas), ou, pontuam que, apesar da miscigenação, temos uma brutal desigualdade étnico-racial ${ }^{2}$.

Por outro lado, apesar da questão étnico-racial estar tão presente no cotidiano das relações sociais brasileiras (como discurso, prática ou performance), conformou-se por um longo período como um tabu. Na verdade, por muito tempo a ideia de que no Brasil se vivia uma Democracia Racial foi hegemônica, e, na medida em que essa perspectiva pregava a não existência de conflitos étnicos ou raciais no país, foi vedada qualquer discussão, debate ou crítica sobre o tema. Algo inconcebível se pensada a partir da realidade brasileira, marcada pelo racismo e por uma história de escravização, expropriação e violência racializadas (MUNANGA, 2004). O que deveria figurar como tema frequente em debates (políticos) no Brasil, restringiu-se a locais e grupos muito específicos da sociedade - sem contarmos, obviamente, os contextos em que esse tema aparece de maneira jocosa ou descomprometida.

Apesar disso, nos últimos vinte anos, por conta da atuação do movimento negro, o debate referente à questão étnico-racial - especificamente acerca da população negra - se ampliou consideravelmente e tomou outros contornos no país. Para além das ações e repercussões na sociedade civil, protagonizadas pelos movimentos sociais, Bernardino (2004) sugere três fatos históricos como influenciadores na atual visibilidade dessas discussões: primeiramente, o reconhecimento pú-

Os dois autores e obras que personificam essas vertentes no debate são, consecutivamente, Gilberto Freyre (Casa Grande e Senzala, 1934) e Florestan Fernandes (A integração do Negro na Sociedade de Classes, 1964). 
blico e oficial em 1995 por parte do Estado brasileiro - no período do governo de Fernando Henrique Cardoso - da existência do racismo na sociedade brasileira. O segundo, o fato de em 2001 o governo brasileiro ter se tornado signatário do documento elaborado em Durban, África do Sul, durante a III Conferência Mundial Contra o Racismo, Discriminação Racial, Xenofobia e Formas Conexas de Intolerância, comprometendo-se a elaborar políticas de combate ao racismo e a discriminação. E, o último, a implementação de políticas de Ações Afirmativas, principalmente em sua modalidade cotas para estudantes negros/as nas universidades UNEB e UERJ no ano de 2003.

Complementando o autor, ressaltamos que a intensificação dessas discussões ocorreu também devido à emergência e visibilização de pesquisas quantitativas de órgãos institucionais brasileiros e de alguns grupos de pesquisa sobre as desigualdades étnico-raciais no Brasil. Estas pesquisas revelavam (e revelam) uma desigualdade gritante entre negros/as e brancos/as na maioria dos indicadores sociais, o que deu maior amplitude à problemática (HASENBALG \& VALLE SILVA,1988; IPEA, 1999; PNUD, 2005; PAIXÃO, CARVANO, MONTOVANELE, et al, 2010).

Por conta desse cenário, esse debate passou a figurar intensamente no cotidiano brasileiro. Com efeito, essas controvérsias tomaram grandes proporções justamente porque feriram ideologias-discursos que perpassam o "corpo da nação" (território, história nacional e povo), em outras palavras, objetivaram desconstruir os mitos da "democracia racial" e do "paraíso racial brasileiro" (ORTIZ, 2003; GUIMARÃES, 1999; MUNANGA, 2004). A pergunta "o que faz do Brasil, Brasil?" foi agregada a pergunta "somos ou não somos racistas?".

Essa intricada trama influenciou nos processos de produção de conhecimento nas universidades brasileiras, pois, as questões gestadas nesse debate foram tomadas como pauta de pesquisa nas ciências humanas em geral - e, até mesmo nas ciências biológicas -, seja para refutar ou para atestar a existência de um problema de natureza étnico-racial no país. Isso pode ser também visualizado na Geografia acadêmica brasileira.

Podemos encontrar abordagens - mesmo que com um conteúdo colonialista e racista - acerca da questão étnico-racial no discurso geográfico brasileiro produzido, principalmente, mas não apenas, entre o fim do século XIX e início do XX (MORAES, 1991a, 1991b, OSÓRIO, 2009). Contudo, ao tempo em que a Geografia se institucionaliza nas universidades brasileiras na década de 1930, notamos 
que o tema se torna rarefeito como objeto de análise. Algo que carece de investigações mais aprofundadas. Ainda assim, debates em torno dessa temática presente na Antropogeografia de Ratzel (1882), nos escritos de Élisée Reclus sobre Escravidão nos Estados Unidos (1860) e mesmo em La Blache (1954 [1922]) não são apropriados pela intelligentsia geográfica, a não ser em obras pouco trabalhadas e sem repercussão ${ }^{3}$.

Essas discussões, contudo, estão sendo retomadas, nos últimos anos, muito influenciadas pelos debates já apresentados nos parágrafos anteriores. Há um esforço de um grupo de autores que estão buscando abordar a temática a partir de uma perspectiva geográfica (SANTOS, 2007, 2010; RATTS, 2003, 2010; CAMPOS, 2005; CARRIL, 2006; ANJOS, 2001, 2005; ALMEIDA, 2010). No que tange à produção das pós-graduações em Geografia, notamos que a produção de teses e dissertações aumenta exponencialmente de 2002 a 2011, acompanhando o período da intensificação dos debates políticos sobre a questão étnico-racial, como apontado acima. Mesmo assim, somos ainda carentes de uma real sistematização do que vem sendo produzido sobre esse assunto na Geografia brasileira.

Assim, pretendemos apresentar, panoramicamente, como a Geografia brasileira se situa nesse debate. Para tal, realizamos um levantamento das teses e dissertações concluídas nos programas de pós-graduação no país, buscando quantificar e sistematizar o que vem sendo produzido no tocante as relações étnico-raciais - com foco na população negra - na Geografia. Cremos, dessa forma, que as teses e dissertações expressam o estado da arte da produção do discurso geográfico no Brasil, bem como, evidencie a dimensão e intensidade de alguns debates realizados na Geografia brasileira institucionalizada ou universitária. Em outros termos, traduzidos pelas teses e dissertações, entendemos que os programas de pós-graduações são um termômetro que indica a aceitação de um tema e como ele é abordado teoricamente pela intelligentsia geográfica. De antemão, ressaltamos que os objetivos que intentamos cumprir aqui são: quantificar as teses e dissertações que abordem a questão étnico-racial nos programas de pós-graduação em Geografia do Brasil; mapear e espacializar essas abordagens; sistematizar as tendências teóricas utilizadas para tratar a temática; e, tentar, ainda que de forma superficial, pontuar as principais referências utilizadas pelos autores/as e verificar as principais lacunas presentes nas abordagens.

\footnotetext{
Trabalhamos com a hipótese de que as obras que correlacionavam a questão étnico-racial e a Geografia - enquanto campo acadêmico no Brasil - podem ter sido invisibilizadas e excluídas dos debates. Isso as levou a não alcançar visibilidade dentro do cenário nacional. Esta hipótese, contudo, também necessita de investigações mais aprofundadas.
} 
Deixamos claro desde já que nosso propósito não é realizar uma abordagem sobre a epistemologia da Geografia e sua relação com a questão racial, mas apresentar um panorama que crie condições para integrarmos abordagens de trabalhos que tratem esse tema na Geografia. Esperamos, desta forma, que esse levantamento contribua para o entendimento da construção e consolidação de linhas de pesquisa na Geografia e permita projetar caminhos a serem trilhados para uma ampliação do foco analítico de nosso campo científico.

$\mathrm{O}$ artigo, desta forma, está organizado na seguinte estrutura: a primeira parte apresenta a metodologia adotada, bem como, os problemas encontrados no processo de levantamento dos trabalhos; a segunda se concentra em abordar a espacialização da temática e a cronologia com que ela vem sendo produzida; na terceira será apresentada uma classificação, agrupamento e análise das teses e dissertações conforme as análises centrais encontradas; e, por fim, teceremos um breve comentário acerca das lacunas e sugestões em torno da questão étnico-racial na Geografia.

\section{Notas sobre os procedimentos metodológicos e seus percalços}

A realização dessa pesquisa tem como sustentação o levantamento de dissertações e teses produzidas nos programas de pós-graduação em Geografia. Para isso, tomamos como referência a metodologia de pesquisa bibliográfica proposta por Ruiz (1978). Assim, no primeiro momento, empreendemos uma observação nas listas de trabalhos concluídos e disponibilizados pelos programas nos sítios das pós-graduações existentes na internet, entre os meses de março e junho de $2012^{4}$. O critério utilizado para a seleção dos trabalhos foi a presença de conteúdos que remetiam e/ou abordavam (direta ou indiretamente) aspectos relativos à população negra nos resumos, palavras chaves, títulos e índices dos trabalhos. Além disso, esquadrinhamos as principais referências, abordagens e categorias utilizadas pelos autores/as das teses e dissertações.

Tendo em vista que não foi realizada pesquisa em loco, somente por meio da internet, encontramos alguns problemas que interferiram em nossa amostragem, os quais seguem destacados abaixo:

i) O sítio de alguns programas pesquisados encontravam-se off-line ou não existiam (também não descartamos a hipótese de não termos encontrado o sítio no momento em que realizávamos a pesquisa) $)^{5}$. Esse é o caso do programa de Pós-Graduação em Geografia da Univer-

\footnotetext{
${ }^{4}$ A Capes exige que todos os programas de pós-graduação no Brasil tenham um sítio, onde devem disponibilizar informações sobre o programa e divulgar a produção realizada pelos discentes e docentes vinculados ao programa.

5 Todos os sítios visitados constavam na lista de avaliação de 2012 realizada pela CAPES dos cursos de pós-graduação em Geografia. <http://www.capes.gov.br/component/content/article/44-avaliacao/4673-geografia>
} 
sidade Federal do Mato Grosso do Sul (UFMS). Quanto ao sítio da Universidade Federal de Rondônia (UNIR), a página encontrava-se em construção no período da visita.

ii) Uma parte considerável do banco de dados dos sítios não estava atualizado no período em que realizamos a pesquisa, faltando a disponibilização de dissertações e teses dos anos mais recentes, 2010 e 2011.

iii) Algumas teses e dissertações produzidas anteriores ao ano de 2000 não estão disponibilizadas nos sítios. Este não é um problema propriamente dos Programas, mas tem a ver com o período em que o uso de ferramentas ligadas a internet se popularizam no Brasil e tornam-se um meio efetivo de divulgação e circulação do conhecimento científico. Assim, o total de sete obras, dentre dissertações e teses, produzidas em universidades que possuem programas de pós-graduação antigos não puderam ser analisados efetivamente, a não ser pelas referências contidas no título das obras. Universidade de São Paulo (USP) e a Universidade Federal do Rio de Janeiro (UFRJ) exemplificam esse problema.

iv) Dois programas, o da Universidade Federal Fluminense (UFF) e o da Universidade Federal do Rio de Janeiro (UFRJ), não apresentam uma sessão na página onde estejam disponíveis as teses e dissertações produzidas pelos discentes. Isso não permite que visualizemos, no conjunto geral, o que o Programa produziu e está produzindo sobre a questão étnico-racial, pois, somente se pode acessar suas produções por meio do portal Capes, onde se encontram disponíveis dissertações e teses de todos os programas de pós-graduação do Brasil.

v) Infelizmente, não podemos operar com a comparação entre o quantitativo geral de trabalhos produzidos na Geografia e os que fazem referência à questão étnico-racial. A produção total não está disponibilizada em nenhum documento científico ou institucional de órgãos que acompanham e regulam as Pós-Graduações. Realizar tal empreitada seria um trabalho que demandaria muitos recursos, tempo e investimento, o que não nos permite o atual momento da investigação.

Acreditamos que apesar da internet ter se popularizado nas universidades, ainda é de forma geral uma ferramenta utilizada parcialmente pelos programas de Pós-Graduação em Geografia como instrumento efetivo de difusão, trocas e circulação de conhecimento produzido. Além disso, constatamos a falta de integração entre os programas de pós-graduação em Geografia no Brasil, especialmente no que toca à circulação de suas produções. Um banco de dados nacional voltado especificamente para a Geografia, não só desconcentraria a circulação e difusão de produções de programas localizados na região Sudeste - que são os mais antigos e, em partes, mais bem estruturados, como facilitaria um levantamento ou pesquisa bibliográfica comparativa - da ordem da qual estamos apresentando aqui. Consideramos essa descentralização urgente, em vista das dificuldades encontradas nesse levantamento, o que certamente se repete em pesquisas semelhantes. 
Apesar disso, devemos ressaltar que frente aos números encontrados por nós, os problemas metodológicos acima citados não interferiram profundamente nos dados finais do levantamento. Da mesma forma, ainda que existam tais problemas, deixar de realizar esta investigação baseada na metodologia aqui explicitada, é abrir mão de uma ferramenta importante para pensarmos a produção em Geografia no Brasil. Pois, apesar das falhas, a internet facilita a realização e desenvolvimento de pesquisas, haja vista que possibilita acessar diferentes trabalhos sem deslocamentos.

A segunda fase do trabalho investigativo refere-se à espacialização dessa produção, o que nos diz, um pouco, onde e com que frequência a temática étnico-racial está sendo debatida/produzida, mostrando tendências expressas nos programas de pós-graduação e, propriamente, na Geografia produzida nas várias localidades e regiões brasileiras.

No que diz respeito à terceira fase, devemos ressaltar que, o principal objetivo dessa pesquisa bibliográfica, além de tentar compreender o atual contexto de produção científica acerca da questão étnico-racial na Geografia, é apontar novos aportes teóricos e evidenciar lacunas. Também, não é nossa intenção impor uma visão sobre a temática como a mais coerente, mas sim, visualizar a geografia e seus conceitos dentro dos trabalhos encontrados, possibilitando tencionar questões, vislumbrar desafios e apontar caminhos. Para isso buscamos: reunir ideias comuns, conectar assuntos complementares entre si e comparar perspectivas divergentes ou opostas. Assim, a partir do levantamento e tentando cumprir tais objetivos, dividimos em quatro eixos temáticos as teses e dissertações encontradas e as analisamos: i) espaço e relações étnico-raciais, ii) identidades e territorialidades negras, iii) geopolítica dos países africanos iv) e território e lugar nas manifestações culturais negras (tópico 3).

\section{Espacialização e quantificação de tendências}

Como mencionado, realizamos uma espacialização e quantificação da produção dos trabalhos sobre a temática racial na Geografia. Buscamos, desta forma, identificar o locus de tais produções e a frequência temporal com que ela vem sendo realizada.

De acordo com o levantamento, temos cinquenta e quatro (54) trabalhos, dentre teses (13) e dissertações (41). Destes, dezesseis (16) dizem respeito à tendência "espaço e relações étnico-raciais"; dezoito (18) à “identidades e territorialidades negras"; dez (10) à "geopolítica dos países africanos" e dez (10) à "território e lugar das manifestações culturais negras". 


\section{Gráfico I - Produções sobre a questão racial por temática}

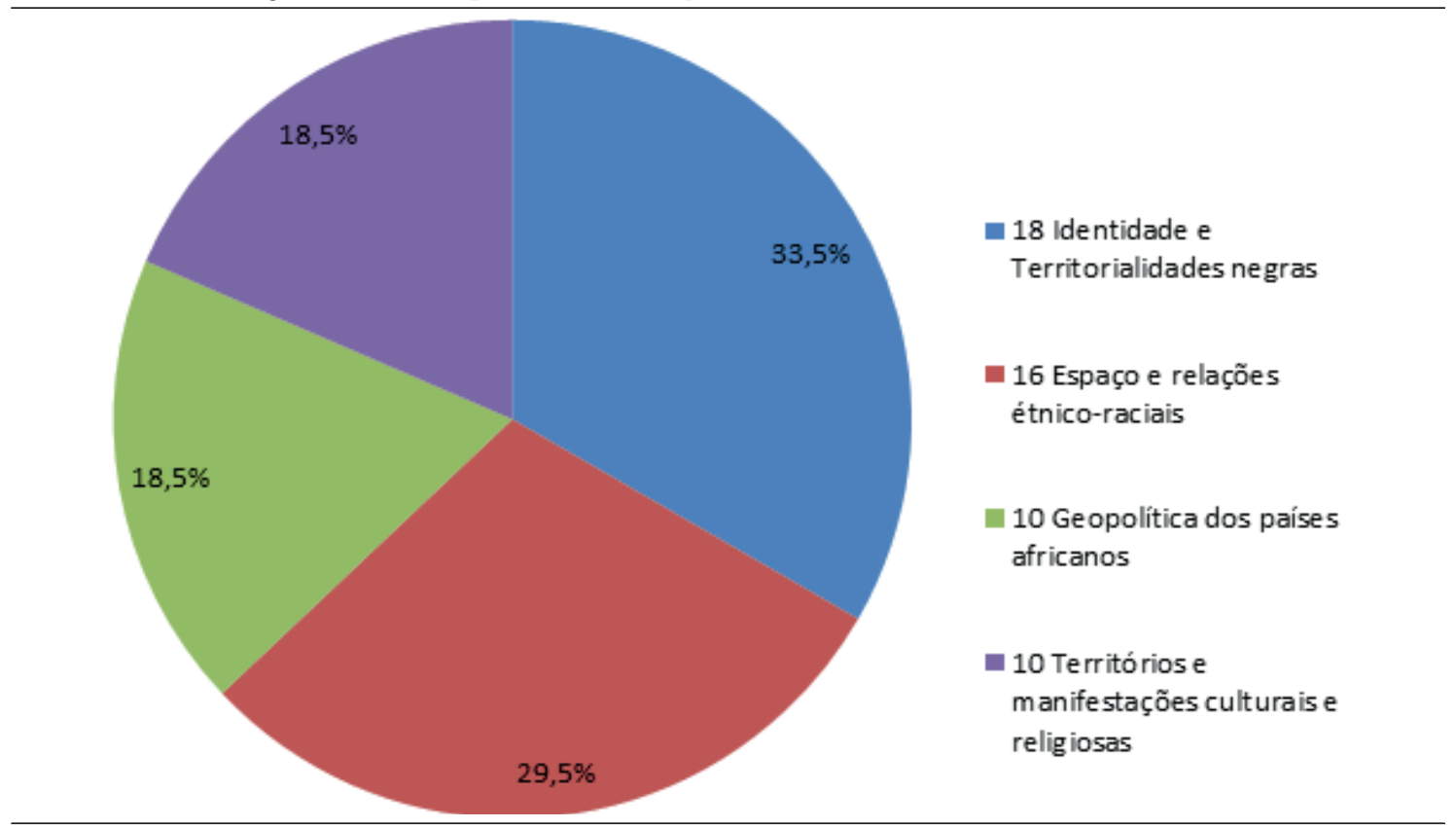

Com base nos dados recolhidos, (ver mapa I), há um predomínio da produção na região sudeste, correspondendo a quase $60 \%$ dos trabalhos realizados. Este alto número se deve principalmente a dois fatores: a região possui o maior número de pós-graduações (um total de quinze), sendo que estas são as mais antigas do país - principalmente os programas localizados no Rio de Janeiro (UFRJ) e em São Paulo (USP) ${ }^{6}$, que juntos apresentam dezesseis (16) trabalhos produzidos. Adjacente a esta constatação, levantamos a hipótese de que por serem centrais e consideradas de maior proeminência, elas atraem estudantes de várias partes do Brasil, abarcando uma multiplicidade de assuntos que acabam por aumentar as possibilidades de projetos que abordem a temática racial. Porém, devemos alertar que na Geografia este fato não representa uma total aceitação no que diz respeito a essa temática, pois se pararmos para analisar, verificaremos que ela ainda ocupa pouco espaço na produção tanto dessas instituições quanto em escala nacional.

As regiões Nordeste e Centro-Oeste juntas possuem quinze (15) programas de pós-graduação, que surgiram no final da década de 1990 e meados dos anos 2000. Ambas apresentam uma quantidade significativa de trabalhos quando tomados como referência outras regiões brasileiras; ao todo estas duas somam vinte (20) trabalhos. Destacamos aqui a UFG como a universidade de onde provém a maior parte dos trabalhos da região Centro-Oeste, oito (08) ao todo. Há um grupo nessa instituição que se dedicou durante os úl-

\footnotetext{
6 A pós-graduação da Universidade de São Paulo (USP) existe desde 1944 e a pós-graduação da UFRJ existe desde 1975. As duas são as mais antigas instituições com Pós-Graduação, bem como, são as universidades que possuem o maior conceito, de acordo com a avaliação da Capes.
} 
timos dez anos a pesquisar as relações étnico-raciais com um viés geográfico, projeto que foi ampliado com a formação em 2008 do Laboratório de Estudos Gênero, Étnico-raciais e Espacialidades - LaGENTE.

Verificamos na região Norte a inexistência de produção voltada para essa temática, enquanto na Sul existem apenas dois trabalhos. A ausência de qualquer produção na primeira decorre principalmente do fato de que só recentemente se constituíram programas de pós-graduação em Geografia. Já na região Sul, apenas dois (02) trabalhos foram encontrados, fato que deve ser problematizado um pouco mais a fundo, pois há nessa região um considerável número de pós-graduações existentes desde a década de 1990. Apesar de existirem Programas que tenham surgido recentemente, ela representa o segundo maior polo de pós-graduações em Geografia do Brasil. Destacamos que não estamos querendo atribuir juízo de valor ao falar que em determinada região as universidades pouco debatem este tema, este fato é patente em todas as regiões do Brasil, mas, o pequeno número de produções indica sim a pouca atenção (ou aceitação) dada a questão racial nessa região. É importante frisar que a invisibilização da população negra no $\mathrm{Sul}^{7}$, principalmente nos processos de produção de conhecimento científico - que difundem ideologias geográficas sobre esse espaço - legitimam e perpetuam práticas de racismo, violência e expropriação. Pois, a teoria não se restringe ao abstrato (SOUZA-SANTOS, 2003), afetando o cotidiano e existência de indivíduos e comunidades inteiras (como as quilombolas). Souza Santos (idem), por exemplo, fala em produção da não existência para problematizar os grupos ou sujeitos que são invisibilizados dentro de determinado espaço (epistêmico, físico ou simbólico). Entendemos que, especialmente na região Sul, mas não se limitando a ela, essa ausência de produção sobre a questão étnico-racial conforma uma situação de "produção de não existência", que reflete, por exemplo, no ensino dessa disciplina, já que quando falamos do Sul, dificilmente destacamos a existência da população negra nesse espaço ${ }^{8}$.

\footnotetext{
7 Segundo dados do censo do IBGE de 2010, 23\% da população da região sul é composta por negros.

8 O tema dos quilombos urbanos poderia ser facilmente abordado quando falamos da região Sul. A comunidade quilombola da família Silva, por exemplo, foi a primeira comunidade a ganhar o título, estando em uma área urbana valorizada, localizada no centro de Porto Alegre. Ademais, essa região concentra um alto número de comunidades negras que buscam ser reconhecidas como Quilombos. O Incra aponta 126 comunidades com processos abertos.
} 


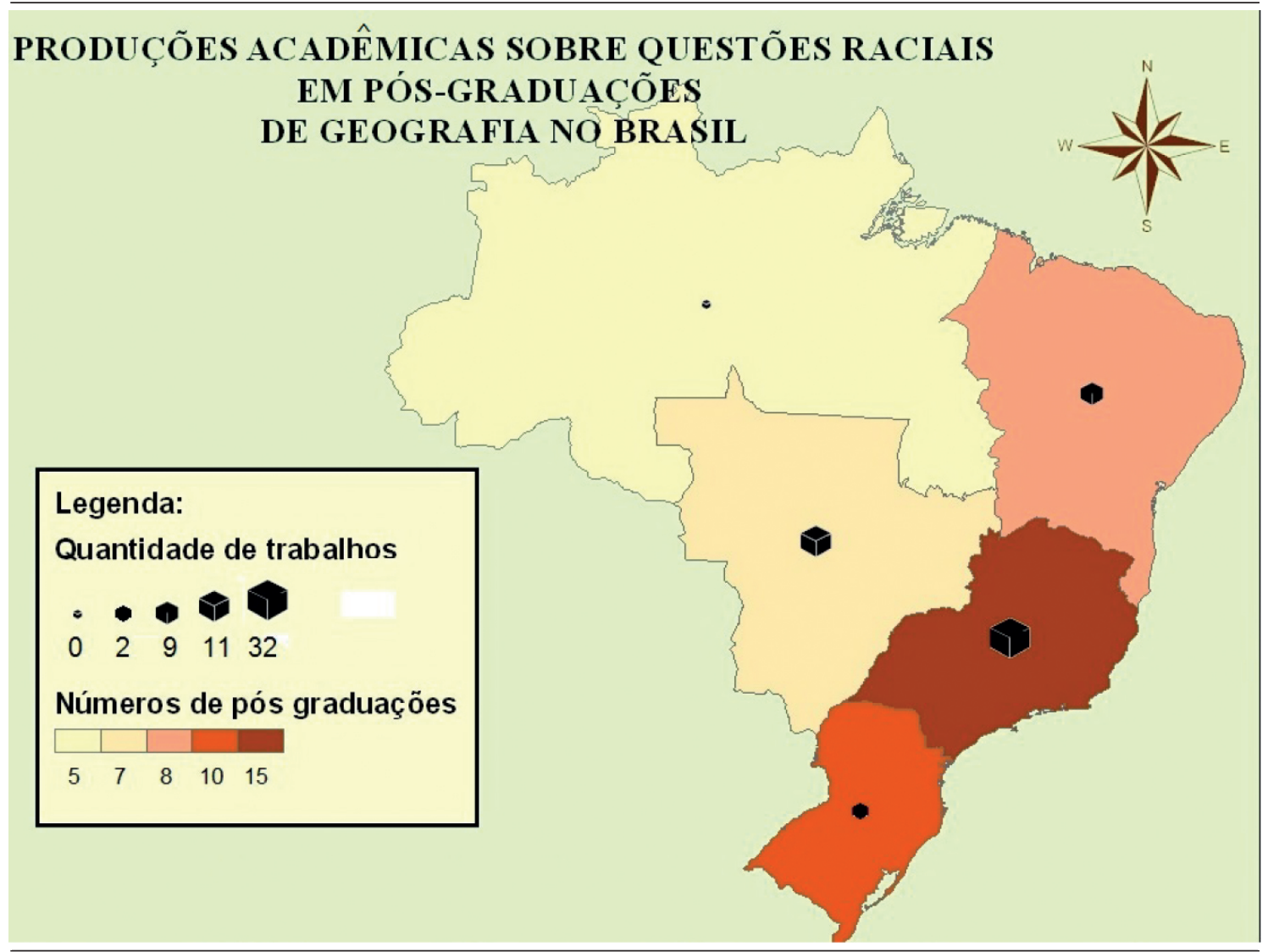

Quanto à cronologia da produção nacional, podemos perceber (de acordo com o gráfico II) que antes de 2000 poucos trabalhos se propunham a debater a questão étnico-racial. Porém, na virada do século, não só há o aumento no número de pós-graduações no Brasil, como também há uma maior disposição de trabalhos acerca dessa temática, o que resultou consequentemente em um aumento significativo de dissertações e teses. Somente entre os anos de 2006 e 2011, trinta e cinco (35) trabalhos foram produzidos nessas pós-graduações brasileiras. 


\section{Gráfico II - Quantidade total de trabalhos produzidos}

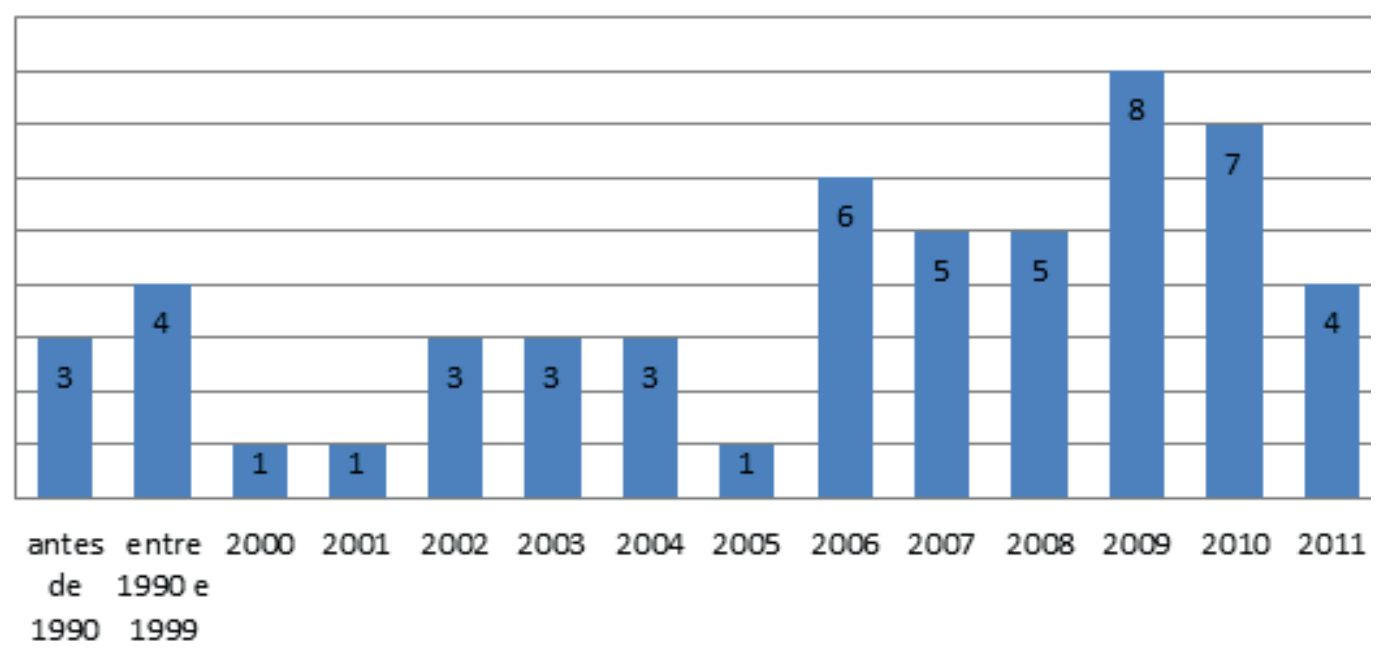

Acreditamos que esse aumento é parte da maior visibilidade da problemática étnico-racial na sociedade brasileira perante as realidades espaciais que a atravessam. Nesse aumento, destacamos a grande quantidade de trabalhos voltados a discutir territorialidades negras, em que, a maioria diz respeito aos processos de territorialização das comunidades remanescentes de quilombo.

Outro fator que deve ser destacado é a contínua e crescente produção de teses, que, apesar de ainda figurar com um número restrito quando comparada à produção de dissertações, tem se tornado frequente desde o ano de 2002.

\section{Gráfico III - Número de teses e dissertações produzidas por ano}

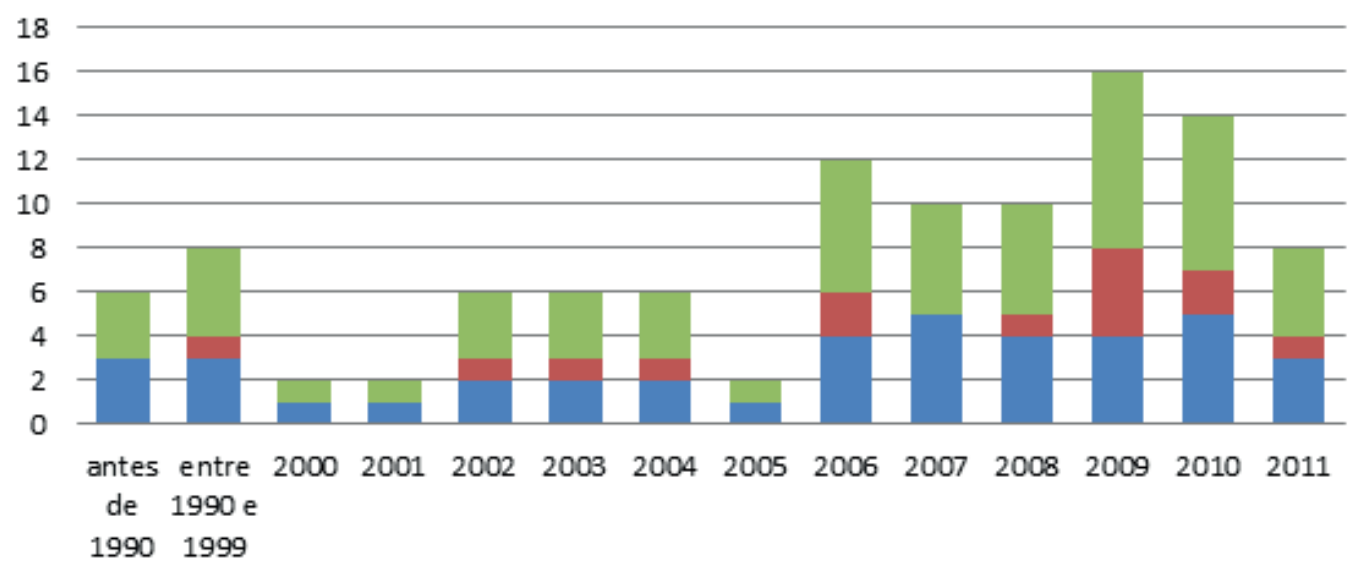

nissertações - Teses $\square$ Total 
Porém, não devemos imaginar que a Geografia apenas passou a trabalhar a questão racial nos últimos anos. O tema da "raça" e sua relação com o território brasileiro foi amplamente explorado sob um viés geográfico por não geógrafos no início do século XX, tendo impactado nas políticas de imigração formuladas pelo Estado em busca do branqueamento da população ${ }^{9}$. Na própria Geografia temos produções sobre a temática racial, contudo, estas parecem ter sido invisibilizadas ou desconsideradas no interior dessa ciência. Um exemplo é a produção de Milton Santos sobre esse assunto. Sua contribuição ao pensamento geográfico e suas teorias sobre o espaço são bastante recordadas, mas pouco se discute a problematização sobre a questão étnico-racial que este fez ao longo de sua trajetória intelectual - cujos trabalhos da década de 50 já tratavam desse tema (CIRQUEIRA, 2010).

\section{Tendências e abordagens Geográficas sobre a questão étnico-racial}

De forma geral, como já assinalado, definimos quatro tendências que compõem as discussões geográficas acerca da questão étnico-racial, a partir das quais também estruturamos as análises que se seguem. São elas: Espaço e relações étnico-raciais; identidades e territorialidades negras; geopolítica dos países africanos; e, território e lugar nas manifestações culturais negras. Na escolha e definição de nossos critérios de agrupamento há perdas - como em toda generalização, contudo, em nossa concepção, mesmo que tenhamos o prejuízo de perdermos de vista as particularidades dos trabalhos, esses conjuntos nos possibilitam enxergar eixos e agendas mais amplos que envolvem o campo (ou os campos) da disciplina Geografia. Além disso, é uma maneira didática de organizarmos e apresentarmos o conjunto das teses e dissertações, ainda que, aqui, não seja possível aprofundarmos tais análises.

\section{Espaço e relações étnico-raciais}

Nessa tendência, ao todo, temos 16 trabalhos. A maioria dos trabalhos foi produzido em universidades da região Sudeste do país, especificamente na USP (uma tese e uma dissertação), na UNESP (duas dissertações), na UFRJ (duas dissertações e uma tese) e na UFF (duas teses). Contudo, há uma considerável produção no Centro-Oeste, especificamente nos programas de pós-graduação em Geografia da UFG (três dissertações) e da UnB (uma dissertação). Na região Nordeste há produção na UFBA (duas dissertações) e

\footnotetext{
9 Um desses trabalhos foi o de João Batista Lacerda, Sur le métis au Brésil, traduzido para o português como Sobre os mestiços no Brasil (1911). Na condição de diretor do Museu Nacional ele representou o Brasil no Congresso Universal das Raças em Londres apresentando esse documento em que estipulava que dentro de 100 anos - que segundo ele corresponderia a três gerações - a população brasileira seria totalmente branca. Outro famoso exemplo é do escritor brasileiro Monteiro Lobato, que recentemente teve cartas de 1938 reveladas. Estas cartas tinham mensagens e conteúdos explicitamente racistas que repudiavam a mestiçagem e lamentavam a não existência de uma Kun Klux Klan no Brasil. Trechos dessas cartas podem ser encontrados no sítio <http://bravonline.abril.com.br/materia/monteiro-lobato-era-racista $>$.
} 
na UFC (uma dissertação). Quanto à temporalidade dessa produção, dois trabalhos foram elaborados na década de 80 e o restante nos anos 2000.

Direta ou indiretamente essas pesquisas são influenciadas pelo contexto de discussões da década de 1980, período em que surge uma série de investigações que desagregaram desigualdade socioeconômica e desigualdade racial, demonstrando que havia disparidades entre ambos (cf. HASENBALG, 2005 [1979]; HASENBALG \& VALLE SILVA, 1988). Diante disso, a maioria dos trabalhos estabelece uma abordagem sociológica da espacialidade que compõe as relações étnico-raciais brasileiras e/ou como as categorias geográficas podem ser utilizadas para o entendimento desse assunto. Os temas mais tratados são a segregação racial e a maneira como as desigualdades étnico-raciais presentes no país se arranjam espacialmente (MALACHIAS, 2006; CARRIL, 2003; OLIVEIRA, 2011; OLIVEIRA, 2005). O foco ou o terreno analítico em praticamente todos esses trabalhos se centra no meio urbano, daí a compreensão da predominância de trabalhos que tratam da segregação de base racial (CAMPOS, 1998, 2006; O’NEILL, 1983; POMPILIO, 1982; DIAS, 2002; FREITAS, 2010). Contudo, partindo também do pressuposto de que a desigualdade racial se inscreve no espaço de forma complexa e com incessante transformação, há trabalhos que intentam compreender os deslocamentos e trajetórias - coletivos e individuais - de pessoas negras; em alguns casos essa dimensão é relacionada com a questão de gênero e do trabalho (SOUZA, 2007; LOPES, 2008; CIRQUEIRA, 2010). Deve ser mencionada também a existência de trabalhos que abordam a atuação e a espacialidade de organizações do movimento negro, ao evidenciar como este movimento estabelece estratégias de atuação que tem como objeto de ação o espaço, ou que ao menos estabelece reverberações políticas neste (SANTOS, 2006; GARCIA, 2001).

Os/as autores/as, as categorias e os conceitos utilizados nas teses e dissertações analisadas compõem um quadro bastante amplo e variado de referenciais - tanto da ciência geográfica, quanto de outras áreas do conhecimento, o que não nos permite traçar um perfil exato desse conjunto, mas sim fazer alguns apontamentos de regularidades comuns. Por exemplo, espacidalidade e território (e territorialidade) são categorias bastante utilizadas nos trabalhos. Dois autores frequentemente citados e utilizados para discutir e conceituá-las são Rogério Haesbaert (2004) e Milton Santos (2004). Igualmente, são utilizadas as noções de raça e etnia para tratar das relações étnico-raciais, e mesmo que em muitos dos trabalhos não haja um aprofundamento conceitual em torno de tais categorias, um autor recorrente para discutir tais noções é o antropólogo Kabengele Munanga (2010). Frente a isso, uma grave falta que se nota é o não aprofundamento sobre as teorias da etnicidade 
e da própria construção social da raça (POUTIGNAT \& STREIFF-FENART, 1998; GUIMARÃES, 1999; MUNANGA, 2004, 2010; QUIJANO, 2005), algo que esteve ausente em todos os trabalhos e que poderia ter amplificado algumas análises.

De forma geral, algo que podemos notar é que a teoria geográfica e as abordagens sobre as relações raciais, na maneira como são tratadas nos trabalhos, não são devidamente imbricadas. Duas tendências podem ser encontradas na forma como tal tema é abordado pelos geógrafos: ou o foco analítico se concentra nas relações étnico-raciais, fundamentado em referências da Antropologia e Sociologia, e se conforma uma espaciologia das relações étnico-raciais; ou, o foco se concentra na teoria geográfica, e as relações étnico-raciais são um apêndice para a aplicação de categorias e conceitos da disciplina. Em outras palavras, poucas vezes nos trabalhos se encontram de fato conceitos e teorias da Geografia e das relações étnico-raciais.

Outro apontamento que pode ser feito é que, apesar da existência de poucos trabalhos na Geografia que tratam desse tema, eles possuem uma extensão temporal que vai até a década de 1980 - sem contar a literatura geográfica estrangeira, principalmente anglo-saxônica, que envolve esse tema (JACKSON, 1987), ainda assim, sempre que se busca teorizar as relações étnico-raciais nas teses e dissertações se recorre - em todos os casos - às referências presentes em outras áreas do conhecimento. Os autores e autoras da Geografia, com raras exceções, não se citam, o que não permite a conformação de diálogos e controvérsias que poderiam desenvolver um campo de análise e discussões sobre essa temática no interior da Geografia. Esse fato, cremos, também corrobora para que ocorra o que mencionamos acima, isto é, para que as teorias geográficas não se encontrem de fato com as teorias das relações raciais, já que as referências são buscadas fora da institucionalidade teórica da disciplina.

\section{Identidades e territorialidades negras}

Neste eixo foi possível encontrar dezoito (18) trabalhos, dos quais mais da metade se concentra na região Sudeste, totalizando dez trabalhos: cinco na USP (duas teses e três dissertações), um na UNESP-PP (dissertação), um na UFF (tese) e dois na UFMG (uma tese e uma dissertação). A outra metade está divida entre Centro-Oeste, com dois trabalhos na UnB (ambas dissertações) e um na UFG (dissertação) e cinco na região Nordeste (todas dissertações) com uma na UFPB e duas na UFBA e na UFPE. A produção que envolve essa temática segue o padrão geral, com apenas quatro trabalhos defendidos até 2005. Posterior a esse período 14 trabalhos se voltaram para a temática.

Os trabalhos classificados neste eixo tratam principalmente da formação, organiza- 
ção e conflitos que perpassam a constituição de territórios negros ao longo dos séculos. Observamos neste aspecto uma abordagem que integra as comunidades remanescentes de quilombo e os territórios construídos com base nas identidades negras; o que envolve tanto a luta pela terra - inclusive institucional, com a luta para se obter a titulação das terras, quanto às resistências que estes grupos conformam.

Desses 18 trabalhos, apenas um não aborda diretamente a questão quilombola, mas, ainda assim, esse assunto aparece como tema em todos os trabalhos, seja os centrados nos processos de territorialização e resistência ou nas formas de produção e modos de vida (LIMA, 2010, ARAUJO, 2011) e a migração dos seus habitantes (JESUS, 2007). Essa quantidade significativa de trabalhos nas pós-graduações - quando comparada aos outros eixos - tem relação direta com a eclosão de conflitos engendrados ao processo de reconhecimento dessas comunidades. O aumento dessa produção - com exceção da dissertação de Ratts (1994) defendida no programa de pós-graduação da USP - só acontece 17 anos após a promulgação do artigo 68 do ato das disposições transitórias de 1988, que reconhece o direito à propriedade para as comunidades remanescentes de quilombos que estejam ocupando as suas terras.

Praticamente todos os trabalhos partiram de uma perspectiva metodológica empírica; com o levantamento histórico da área e entrevista com moradores (fundamentados em metodologias da história oral), principalmente moradores mais antigos, como é explicitado. Junto a isso, são utilizados documentos, laudos territoriais e levantamentos sobre as condições da área de estudo. Em alguns trabalhos os pesquisadores vão ainda mais longe e fazem uma leitura sobre as origens histórico-geográficas dos moradores. O tema da preservação ambiental também está presente em relação à coexistência desses grupos com áreas preservadas, incluindo uma parte da Mata Atlântica (SILVA, 2004, 2008). São retratadas ainda as dificuldades em se manter no território, não só devido a disputas com latifundiários, empresários ligados ao agronegócio (FERREIRO, 2002, 2009) ou outros agentes, mas também, pela dificuldade financeira que os quilombolas atravessam, já que, algumas dessas áreas foram incorporadas ao urbano, devido ao avanço das cidades sobre antigas áreas agrícolas. Dentro dessa diversidade de problemáticas referentes às comunidades quilombolas tem-se ainda o debate em torno dos saberes produzidos nas comunidades, inclusive com fins medicinais (GOMES, 2009).

Entre as referências comuns mais utilizadas de autores da geografia, encontramos Rogério Haesbaert (1999, 2002, 2004), Marcelo Lopes de Souza (2001), Claude Raffestin (1993) e Milton Santos (2004). Estes autores são empregados para conceituar o território, estando esta categoria presente em praticamente todos os trabalhos, cujos quilombos são apreendidos como territórios construídos cultural e politicamente - principalmente no 
que dizem respeito aos seus direitos de propriedade. Porém, alguns desses trabalhos só abordam o conceito de território em um momento muito específico da análise, o que gera uma perda do potencial analítico em torno do conceito.

Muitos usam Milton Santos (2004) também para elucidar questões sobre o espaço geográfico. Antônio Robert Moraes $(2000,2002)$ e Bertha Becker (1990) também aparecem na discussão sobre a formação do Estado e a geopolítica brasileira, e o geógrafo inglês David Harvey (1992) aparece quando há alguma abordagem sobre as cidades. Nas explicações sobre as comunidades remanescentes de quilombo, o geógrafo Rafael dos Anjos Sanzio (2001, 2005a, 2005b) também é citado de forma constante, principalmente as suas produções cartográficas. Entre os autores de outras áreas do conhecimento, têm-se principalmente sobre a temática quilombola, autores como Alfredo Wagner (2006), Ilka Boaventura (2004), e Flávio Gomes (2004). Já Lilian Schwarcz (1993) aparece quando o assunto são as relações raciais no Brasil.

É possível enxergar uma constante tentativa em correlacionar as teorias geográficas com as perspectivas que tratam das relações raciais no Brasil, e em que essas relações implicam no reconhecimento das comunidades quilombolas. Porém, em alguns casos, estas abordagens aparecem dissociadas umas das outras. Nesses casos há uma análise muito mais antropológica, que não se atenta para as dimensões espaciais que envolvem ou implicam relações de poder e desigualdade. Assim, é deixado de fora uma observação mais apurada sobre os micro-processos territoriais da comunidade e o modelo de ordenamento territorial excludente, implementado em escala nacional (e transnacional) nos últimos anos, discutidos na geografia (PORTO-GONÇAVES, 2001). Mas destaquemos que temas como segregação, migração, desterritorialização, produção agrícola e conflitos territoriais estão presentes, ainda que eles não ocupem uma parte significativa dos trabalhos.

Ademais é preciso evidenciar que 18 trabalhos produzidos neste tema é um número ao mesmo tempo importante, pois mostra que os geógrafos têm começado a tratar o tema, mas ainda assim de maneira irrisória, frente a quantidades de comunidades que vêm lutando pelo seu direito, utilizando suas referências territoriais como um dos principais mecanismos de defesa frente às pressões de múltiplos agentes. Para termos uma ideia, apesar do INCRA listar um número pouco superior a mil comunidades remanescentes de quilombo exigindo direito a terra e a Fundação Cultural Palmares apontar mil e oitocentas comunidades certificadas, outras leituras chegam a indicar a presença de mais de três mil comunidades com possibilidade de lutar pela titulação do território, como ilustra o mapa abaixo: 


\section{Mapa II - Comunidades e territórios quilombolas Auto-Identificados no Brasil.}

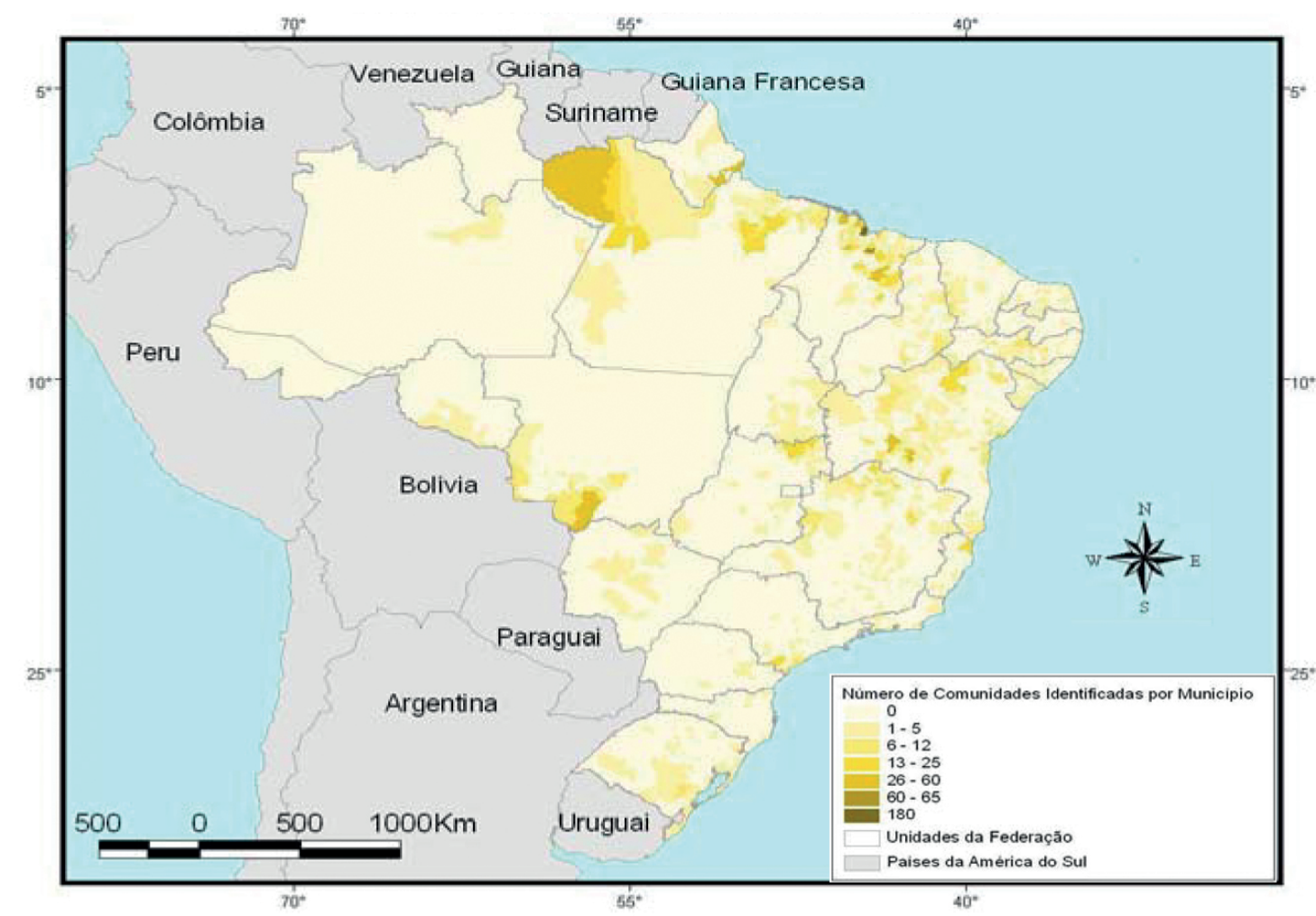

Fontes - FCP, UNB, SEPRIR, INCRA, UFAP, Programa Raízes, CEDENPA, NAEA (levantamento realizado por TRECCANI 2006)

\section{Geopolítica dos países africanos}

Ao todo, relativo a essa temática, foram encontrados 10 trabalhos produzidos na sua maior parte no eixo Rio-São Paulo; na UFRJ (três dissertações e uma tese) e USP (duas dissertações e duas teses). Os outros dois trabalhos, ambos dissertações, foram defendidos na UFSC e UEPG. Uma análise temporal mostra que metade desses trabalhos foi gerado entre os anos de 2009 e 2012, a outra parte é da década de 90 e o mais antigo de 1977 na USP.

Os debates encontrados versam sobre aspectos econômicos, políticos e culturais de países da África. Há, no entanto, uma maior concentração nas questões sobre geopolítica dos países localizados no continente, no que tange tanto às relações intra-continentais como também nas relações econômicas e diplomáticas dos países africanos com o Brasil 
(WILKEN, 2009, PENHA, 1998, SCHUTZER, 2009, SALACHE, 2009 SORÉ, 1977). Há ainda abordagens que contemplam o modo de vida de comunidades africanas e os conflitos e disputas existentes em algumas localidades do continente (FERNANDES, s/d), principalmente em torno da urbanização e segregação presente em alguns países como Zimbábue e Moçambique (SILVA, 2011, BAIA, 2009, BARBOSA, 1994). A experiência e consequência do período colonial e do momento posterior a Guerra Fria, também marca grande parte dos trabalhos.

Alguns autores apontam uma ligação entre Brasil e o continente africano, a partir da grande imigração de africanos escravizados para o Brasil entre os séculos XVI e XIX, porém, não é dado um foco a essa questão, estando presente mais como uma rápida observação na maioria dos trabalhos. Ainda que isso não seja um problema, já que não é foco dos autores, esse seria um ponto importante a se recuperar e tratar na Geografia, já que esta relação marca toda a trajetória política, social e econômica do processo de formação e consolidação do território brasileiro.

Há uma forte presença de autores da Geografia e, dentre os mais citados, estão Bertha Becker (1993), Manuel Corrêa de Andrade (1989), Milton Santos (2000) e Willian Vesentini (1987) - sempre nas abordagens sobre o contexto geopolítico entre os países. Porém, nota-se uma ausência de pesquisadores oriundos de países africanos na bibliografia, recorrendo-se sempre, mesmo nos trabalhos sobre o contexto de países específicos, a autores europeus ou brasileiros. Ainda assim, é preciso destacar que ao abordar a geopolítica dos países africanos, esses trabalhos trazem uma contribuição essencial, além de suprir uma das principais lacunas da Geografia brasileira, que por vezes desconsidera a dinâmica econômica e política desses países.

A principal ausência sentida nos temas sobre África é os que abordam as representações sobre o continente construídas e reproduzidas no Brasil. Isso é grave e tem um rebatimento no âmbito do ensino de Geografia - tanto básico como superior --, que acaba perpetuando leituras em que a África aparece unicamente representada como um espaço de miséria, pobreza e conflitos. Ademais, os africanos quase sempre são representados por imagens de fome, clandestinidade e doenças - principalmente referentes ao vírus HIV. Essas imagens, repetidamente construídas, transmitem ideologias geográficas negativas sobre o continente. Um passo para desconstruir essas geografias imaginativas é realizado por Hernandez (2005) no livro A África na sala de aula, porém, no campo da Geografia, como podemos ver, pouco esforço se tem feito e a produção realizada até o momento parece não contemplar o campo das representações. 


\section{Território e lugar nas manifestações culturais negras}

Dez trabalhos perfazem essa tendência. De acordo com o levantamento realizado, os mesmos foram produzidos nos últimos dez anos, sendo o primeiro elaborado no ano de 2003 e o último no ano de 2011. Destes, três (03) dissertações e uma (01) tese foram produzidos no programa da UFG e uma (01) dissertação na UFBA. O restante dos trabalhos foi elaborado em universidades da Região Sudeste: na UFRJ (uma tese), na UFF (uma tese e uma dissertação), na USP (uma dissertação) e na UFMG (uma dissertação).

Os trabalhos que compõem o tópico território e lugar nas manifestações culturais negras realizam abordagens acerca dos aspectos culturais que compõem as permanências e performances culturas relativas à população negra ou com marcante influência africana. Todos os trabalhos dessa tendência abordam temas relacionados à religiosidade, sejam elas referentes ao catolicismo popular - como as Congadas e as Irmandades dos Homens Pretos (SOUSA, 2011; RODRIGUES, 2008; PAULA, 2010), ou, efetivamente, as religiões de matriz africana, como a Umbanda e o Candomblé (MELLO, 2004; KINN, 2006; CARNEIRO, 2009; TEIXEIRA, 2009; DIAS, 2003). Há abordagens que tentam compreender a cultura negra na contemporânea, lançando olhar especificamente sobre territorialidades do Hip-hop na metrópole (OLIVEIRA, 2006).

“Território" e "lugar" são categorias bastante utilizadas nos trabalhos mencionados. Por meio destas categorias se busca enfatizar os aspectos simbólicos - ou os geosímbolos - que se inscrevem no espaço. Do ponto de vista teórico, as teses e dissertações têm um leque amplo de influências, das quais observamos com maior incidência abordagens relacionadas à "Geografia cultural”, à Antropologia e aos Estudos Culturais. Autores muito citados para fundamentar as leituras de uma grande parte dos trabalhos - tendo em vista que os mesmos focam a religiosidade - são Roger Bastide (1985) e Muniz Sodré (1983), dois clássicos das leituras que analisam referências e resignifacações de influências africanas na cultura brasileira. O principal objeto da abordagem desses autores é justamente as religiões de matriz africana, onde se encontram mais pulsantes uma africanidade, o que de alguma forma justifica a presença constate dos autores nas discussões realizadas nos trabalhos analisados. No que tange à Geografia, autores como Claude Raffestin (1993) e Rogério Haesbaert $(1999,2004)$ são empregados na maior parte dos trabalhos para conceituar a categoria território, enquanto Paul Claval (2001) aparece para fundamentar e justificar uma abordagem cultural no interior da disciplina. Essas referências, e outras, são utilizadas - muitas das vezes - em contraposição a leituras marxistas ou da economia política na Geografia. Contudo, enfatizando em demasiado uma posição em defesa de uma abordagem cultural, são descartados aspectos importantes dessas correntes teóricas que 
poderiam complexificar algumas leituras que envolvem desigualdades relacionadas às manifestações culturais.

Diante disso, uma das críticas que podemos levantar acerca de alguns trabalhos é o pouco investimento em análises que tratam das relações de poder e desigualdades nas manifestações culturais, sendo religiosas ou de outras ordens. Muitas das abordagens se reduzem, quase que unicamente, aos aspectos simbólicos. Isso é problemático, pois, em si essas manifestações já trazem, implícita ou explicitamente, discursos e performances que evidenciam uma situação, passada ou presente, de violência; que envolve um grupo que historicamente é subalternizado. Por outro lado, estas mesmas manifestações estão situadas em condições precárias, tanto econômicas, quanto espaciais, ou seja, na maioria dos casos, os grupos que realizam essas práticas são de origem pobre e estão situados em lugares degradados. Por outro lado, ainda que sejam discutidas relações de poder do ponto de vista espacial ou territorial, como processos de segregação e desterritorialização, é olvidado em algumas análises relações de poder que implicam a racialidade. Obviamente em muito dos trabalhos esse não é o foco, contudo, muitas das performances, ritos e liturgias dessas manifestações estão calcadas nos horrores e na violência da escravidão, bem como, nas experiências contemporâneas desses sujeitos, cuja a corporeidade ainda rememora e impõe uma condição de subalterno divido ao racismo (GILROY, 2001; HALL, 2006; SODRÉ, 1988; MARTINS, 1997). Assim, ao negar essa dimensão perde-se de vista parte do entendimento das práticas, rituais e performances desses grupos e da própria manifestação, bem como, dos processos que o inferiorizam e estigmatizam ambos - sujeitos e manifestações culturais.

\section{CONSIDERAÇÕES FINAIS}

O principal objetivo aqui foi sistematizar a produção acerca das relações étnico-raciais nos programas de pós-graduação em Geografia, contudo, de alguma maneira, também ficaram expressas algumas tendências e ausências acerca desse tema. Com base no levantamento, ao compararmos a produção entre o período anterior e posterior ao ano 2000, fica nítido - mesmo que timidamente - que a temática racial começa a se mostrar presente nas abordagens geográficas. Porém, devemos enfatizar que o número ainda é irrisório ante a ampla dimensão em que o debate insurge atualmente na sociedade brasileira, no qual a Geografia pode contribuir.

A quantidade de agendas que relaciona a Geografia com estes estudos multiplica-se. 
Para nos atermos a apenas alguns trabalhos encontrados no levantamento, podemos falar de: manifestações culturais materializadas em expressões políticas; o número cada vez maior de comunidades remanescentes de quilombos exigindo direito ao território; a segregação nas cidades, em que o recorte racial é explícito; e o estudo da Geografia dos países africanos, no que tange os aspectos econômicos, políticos e jurídicos.

Uma das lacunas mais graves que encontramos é a falta de produção sobre a questão étnico-racial e educação. Nos últimos anos, tem havido um debate intenso em torno da lei 10.639/03, que obriga a implementação no ensino básico de conteúdos sobre a história da África e dos afrodescentes no Brasil; suas lutas e importância na formação cultural, econômica e política do território brasileiro. Este dispositivo jurídico, mais que obrigar a inserção de uma gama de conteúdos no currículo, nos dá a possibilidade de formular outras leituras sobre a formação do território brasileiro, questionando o papel subalternizado do negro na organização do espaço e abrindo uma ampla agenda de estudos fora dos moldes eurocêntricos. Contudo, pelo que notamos, as Pós-Graduações têm passado ao largo desse importante debate. Apesar de a Geografia ser uma disciplina presente no ensino básico, nenhum trabalho encontrado problematizou essa temática e a lei, ou, ao menos, dedicou um mínimo espaço para a discussão do ensino de Geografia.

Frente a esta lacuna, aliada muitas vezes a falta de um aporte teórico que possibilite a problematização da temática racial, observamos alguns caminhos pouco trilhados na teoria geográfica e que podem render bons estudos.

Um desses caminhos que podemos seguir ao tratar desses debates é aquele que autores da teoria do giro decolonial vêm traçando, ao buscar a superação do eurocentrismo impregnado nas Ciências Sociais e totalitarismo epistêmico - que visa a indicar o que é ou não digno de estudo. Nesses teóricos o pensamento da diferença de classes não é o único a ser considerado, devendo atentar para a colonialidade presente no padrão mundial do poder capitalista moderno. ${ }^{10}$ Dessa forma, conceitos como "sistema-mundo moderno-colonial", "colonialidade do poder, do ser e do saber", bem como a compreensão da raça como construção social e elemento ordenador do território passam a ser fundamentais para o estudo de uma Geografia comprometida com os sujeitos. Entender que as classificações sociais impregnam nosso imaginário e constituem hierarquias que se materializam no espaço deve ser outro importante ponto de partida.

\footnotetext{
${ }^{10}$ A colonialidade é um dos elementos constitutivos e específicos do padrão mundial do poder capitalista. Sustenta-se na imposição de uma classificação racial/étnica da população do mundo como pedra angular do referido padrão de poder e opera em cada um dos planos, meios e dimensões, materiais e subjetivos, da existência social quotidiana e da escala societal. Origina-se e mundializa-se a partir da América. (QUIJANO, 2010, pág. 84)
} 
Com essa breve artigo sobre a produção nas pós-graduações referentes as questão étnico-racial na Geografia, esperamos não só demonstrar que a Geografia ainda pouco trabalha a temática, mas, também, estimular as produções, especialmente nas lacunas verificadas, contribuindo para a queda das barreiras sociais que são impostas ao/à negro/a no cotidiano da sociedade brasileira.

\section{REFERÊNCIAS}

1. ALMEIDA, Alfredo Wagner Berno de. “Os quilombos e as novas etnias" In: O’DWYER, Eliane Cantarino, org. Quilombos: identidade étnica e territorialidade. Rio de Janeiro: ABA/ Editora da FGV, 2002.

2. ALMEIDA, Maria Geralda de. Territórios de quilombolas: pelos vãos e serras dos Kalunga de Goiás - patrimônio e biodiversidade de sujeitos do Cerrado. Ateliê Geográfico. Edição especial. Vol. 4, No 9 (2010) p. 36-63.

3. ANDRADE, Manuel Correia de. Geopolítica do Brasil. São Paulo: Ed. Ática, 1989.

4. ANJOS, Rafael Sanzio Araújo dos. O Espaço Geográfico dos Remanescentes de Antigos Quilombos no Brasil. In: Terra Livre. São Paulo: n. 17. 20 semestre/2001, p. 139-154.

5. . A África, a educação brasileira e a Geografia. In: BRASIL. Educação anti-racista: caminhos abertos pela lei 10.639/03. Brasília: MEC, SECAD, 2005a. p. 167-184.

6. ___ Territórios das comunidades quilombolas no Brasil: segunda configuração espacial. Brasília: Mapas Editora \& Consultoria, 2005b.

7. BASTIDE, Roger. As Religiões Africanas no Brasil. São Paulo: Pioneira, 1985.

8. BECKER, Bertha. Amazônia. São Paulo: Ática, 1990.

9. A Geografia e o resgate da Geopolítica. Revista Brasileira de Geografia, Rio de Janeiro, ano 50, n. especial, t. 2. Rio de Janeiro: IBGE, 1988. pp. 99-126.

10. BERNARDINO, Joaze; Apresentação. In: BERNARDINO, J.; GALDINO, D. (orgs.). Levando a raça a sério. Rio de Janeiro: DP\&A, 2004. p. 173-188.

11. CARRIL, Lourdes de Fátima Bezerra. Quilombo, favela e periferia: a longa busca da cidadania. São Paulo, Annablume, 2006.

12. CLAVAL, P. A geografia cultural. Florianópolis. Ed. UFSC. 2001.

13. DESIGUALDADE racial no Brasil: Evolução das condições de vida na década de 90. Rio de Janeiro: IPEA, 2001.

14. GILROY, Paul. O Atlântico Negro: modernidade e dupla consciência. São Paulo; Editora 34; Rio de Janeiro: Universidade Cândido Mendes, Centro de Estudos Afro-Asiáticos, 2001.

15. GOMES, Flávio dos S. Histórias de quilombolas: mocambos e comunidades de senzalas no Rio de Janeiro, século XIX. São Paulo: Companhia das Letras, 2006. 
16. GUIMARÃES, Antônio S. G. Racismo e anti-racismo no Brasil. São Paulo: Ed. 34, 1999.

17. HAESBAERT, Rogério. O mito da desterritorialização. Rio de Janeiro: Bertrand Brasil, 2004.

18. . Territórios alternativos. São Paulo: Contexto, 2002.

19. __ Identidades Territoriais. In: CORREA, Roberto Lobato, ROSENDAHL, Zeny. (Orgs). Manifestações da cultura no espaço. Rio de Janeiro: EdUERJ, 1999, pp. 167-190.

20. HALL, Stuart. Pensando a diáspora: reflexões sobre a terra no exília. Org. SOVIK, Liv. Da diáspora. Belo Horizonte: Ed. UFMG, 2006.

21. HARVEY, David. A condição pós-moderna. São Paulo: Loyola, 1992.

22. HASENBALG, Carlos. Discriminação e desigualdades raciais no Brasil.2a edição, Belo Horizonte: Editora UFMG; Rio de Janeiro: IUPERJ, 2005 [1979].

23. HASENBALG, Carlos; VALlE SILVA, Nelson do. Estrutura Social, Moblidade e Raça. São Paulo: Vértice, 1988.

24. HERNANDEZ, Leila leite. A África na Sala de Aula. São Paulo: Selo Negro, 2005.

25. JACKSON, Peter (org.). Race and Racism: essays in social geography. London: Unwin Hyman, 1987.

26. LEITE, Ilka Boaventura. O legado do testamento: a Comunidade de Casca em perícia - 2 ed.Porto Alegre: Editora da UFRGS; Florianópolis: NUER/UFSC, 2004.

27. MARTINS, Leda Maria. Afrografias da memória. Belo Horizonte: Mazza Edições, 1997.

28. MORAES, Antônio Carlos Robert. Ideologias geográficas: espaço, cultura e política no Brasil. São Paulo: Hucitec, 1991a.

29. __ Notas sobre identidade nacional e institucionalização da Geografia no Brasil. In: Estudos Históricos. Rio de janeiro, vol. 4, n 8, 1991b. p. 166-176.

30. Bases da formação territorial do Brasil. O território colonial brasileiro no "longo" século XVI. São Paulo: Hucitec, 2000.

31. _ Território e História no Brasil. São Paulo: Hucitec / Annablume, 2002.

32. MUNANGA, Kabengele. Rediscutindo a Mestiçagem no Brasil: Identidade Nacional versus Identidade Negra. Belo Horizonte: Autentica, 2004. . Mestiçagem como símbolo da identidade brasileira. IN: SANTOS, Boaventura de Souza \& MENESES, Maria Paula. Epistemologias do Sul. São Paulo: Cortez, 2010 p. 444-454

33. ORTIZ, Renato. Cultura brasileira e identidade nacional. São Paulo: Brasiliense, 2003.

34. PAIXÃO, Marcelo, CARVANO, Luiz M., MONTOVANELE, Fabiana \& ROSSETTO, Irene (orgs). Relatório anual das desigualdades raciais no Brasil; 2009-2010. Rio de Janeiro: Garamond, 2010.

35. PORTO-GONÇALVES, Carlos Walter. Da Geografia às Geo-grafias: Um Mundo: Em Busca de Novas Territorialidades. Apresentado na II Conferência Latinoamericana y Caribenha de ciências sociais. México, 2001. 
36. A reinvenção dos territórios: a experiência latino-americana e caribenha. In: Ceceña, Ana Esther (org). Los desáfios de las emanciopaciones en un contexto militarizado. Argentina: CLASCO, 2006, pp. 151-197.

37. POUTIGNAT, Philippe e STREIFF-FENART, Jocelyne. Teorias da Etnicidade seguido de grupos étnicos e suas fronteiras de Fredrik Barth. Traduzido por: Elcio Fernandes. São Paulo: Fundação Editora da UNESP, 1998.

38. QUIJANO, Anibal. Colonialidade do poder e classificação social. IN: SANTOS, Boaventura de Souza \&MENESES, Maria Paula. Epistemologias do Sul. São Paulo: Cortez, 2010, p. 84-130

39. RAFFESTIN, Claude. Por uma Geografia do Poder. São Paulo: Editora Ática S.A., 1993.

40. RATTS, Alex. A geografia entre as aldeias e os quilombos: territórios etnicamente diferenciados. In: ALMEIDA, M. G.; RATTS, A. (org.). Geografia: leituras culturais. Goiânia: Alternativa, 2003. p. 29-49.

41. __ As etnias e os outros: as espacialidade dos encontros/confrontos. In: Espaço e cultura, UERJ, Rio de Janeiro, No 17-18, Jan/Dez de 2004. p.77-89.

42. - Geografia, relações étnico-raciais e educação: a dimensão espacial das políticas de ações afirmativas no ensino. In: Terra Livre: Crise, práxis e autonomia: espaços de resistência e de esperanças. São Paulo/SP. Ano 26, v. 1, n. 34, jan-jun/2010. p. 125-140.

43. RELATÓRIO de Desenvolvimento Humano: racismo, pobreza e violência. Brasília: PNUD, 2005.

44. RUIZ, J. A. Metodologia cientifica. São Paulo: Editora Atlas, 1978.

45. SAID, Edward. Orientalismo: o oriente como invenção do Ocidente - São Paulo: Companhia das Letras, 2007.

46. SANTOS, Boaventura de Souza. Para uma sociologia das ausências e uma sociologia das emergências. In: Conhecimento prudente para uma vida decente. Cortez, 2003.

47. SANTOS, Milton. A natureza do espaço. $4^{\mathrm{a} e d}$. São Paulo: EDUSP, 2004a.

48. ___ O retorno do território. In: SANTOS, M.; SOUZA, A.M. (Orgs.). Território, globalização e fragmentação. São Paulo: Hucitec/Anpur, 1994. p.15-20.

49. . Por uma outra globalização: do pensamento único à consciência universal. Rio de Janeiro: Record, 2000.

50. SANTOS, Renato Emerson dos (org.) Diversidade, espaço e relações étnico-raciais: O negro na geografia do Brasil. Belo Horizonte: Autêntica, 2007.

51. ___ Ensino de Geografia e currículo: questões a partir da lei 10.639. In: Terra Livre: Crise, práxis e autonomia: espaços de resistência e de esperanças. São Paulo/SP. Ano 26, v. 1, n. 34, jan-jun/2010. p. 141-160.

52. SCHWARCZ, Lilia Moritz. O espetáculo das raças. São Paulo: Companhia das Letras,1993.

53. SEYFERTH, Giralda. Construindo a nação: hierarquias raciais e o papel do racismo na política de imigração e colonização In: Maior, Marcos Chor \& Santos, Ricardo Ventura. Raça, Ciência e Sociedade Rio de janeiro - FrioCruz/CBB 1996, p. 41-58. 
54. SODRÉ, Muniz. A Verdade Seduzida. Por um conceito de cultura no Brasil. Rio de Janeiro: Codeon, 1983.

55. SOUZA, Marcelo José Lopes de. O território: sobre espaço e poder, autonomia e desenvolvimento. In: CASTRO, Iná Elias de et al. Geografia: Conceitos e Temas. $3^{\mathrm{a}}$ ed. Rio de Janeiro: Bertrand Brasil, 2001, p. 77-116.

56. VESENTINI, José William. A capital da geopolítica. 2a Ed. São Paulo: Ática, 1987.

\section{REFERÊNCIAS (espaço e relações étnico-raciais)}

57. CAMPOS, Andrelino de Oliveira. "Do Quilombo à Favela: o tráfico de drogas enquanto estratégia de sobrevivência ilegal nos marcos de uma ordem segregacionista”. PPG-UFRJ (Dissertação de mestrado): Rio de Janeiro, 1998.

58. _. O planejamento urbano e a "invisibilidade" ' dos afrodescendentes: discriminação étnico-racial, intervenção estatal, segregação sócio-espacial na cidade do Rio de Janeiro. PPG-UFRJ (Tese de doutorado): Rio de Janeiro, 2006.

59. CARRIL, Lourdes de Fátima Bezerra. Quilombo, Favela e Periferia: a longa busca da cidadania. Programa de Pós-Graduação em Geografia Humana -USP (Tese de Doutorado): São Paulo, 2006

60. CIRQUEIRA, Diogo Marçal. Entre o corpo e a teoria: a questão étnico-racial na obra e na trajetória de Milton Santos. Programa de Pós-graduação em Geografia - IESA/UFG (Dissertação de mestrado): Goiânia, 2010.

61. CONCEIÇÃO, Marcus Vinícius Pinheiros da. Rugosidades étnicas e a espacialidade do preconceito racial. Programa de Pós-graduação em Geografia - Unesp Presidente Prudente (Dissertação de mestrado): Presidente Prudente, 2004.

62. DIAS, Clímaco Cesar S. Carnaval de Salvador: Mercantilização e Produção de Espaços de Segregação, Exclusão e Conflito. Programa de Pós-Graduação em Geografia - UFBA (Dissertação de mestrado): Salvador, 2002.

63. FREITAS, Fabiana Lucas da S. A territorialidade da criminalidade violenta no bairro jardim das oliveiras - Fortaleza/CE. Programa de Pós-Graduação em Geografia - UFC (Dissertação de mestrado): Salvador, 2010.

64. GARCIA, Antônio dos Santos. As Mulheres da Cidade D’Oxum: Relações de Gênero, Raça e Classe e Organização Espacial do Movimento de Bairro em Salvador. Programa de Pós-Graduação em Geografia - UFBA (Dissertação de mestrado): Salvador, 2001.

65. LOPES, Renata Batista. De casa para outras casas: trajetórias socioespaciais de trabalhadoras domésticas residentes em aparecida de goiânia e trabalhadoras em Goiânia. Programa de Pós-graduação em Geografia - IESA/UFG (Dissertação de mestrado): Goiânia, 2008. 
66. MALACHIAS, Antonio Carlos. Geografia e relações raciais: desigualdades sócio-espaciais em preto e branco. Programa de Pós-graduaçao em Geografia Humana -USP (Dissertação de mestrado): São Paulo, 2006.

67. O’NEILL, Maria Mônica Vieira Caetano. “Segregação racial: um estudo do caso”. PPG-UFRJ (Dissertação de mestrado): Rio de Janeiro, 1983.

68. OLIVEIRA, Denilson Araújo de. Por uma Geografia das Relações Raciais no Rio de Janeiro. Programa de Pós-graduação em Geografia - UFF (Tese de doutorado): Niterói, 2011.

69. OliVEIRA, Luana Pare de. O Espaço de São Miguel dos Pretos: Arquitetura e Territorialidade Africanas no Sul do Brasil. Programa de Pós-graduaçao em Geografia - UnB (Dissertação de Mestrado):Brasília, 2005.

70. POMPILIO, Maria José. Segregação étnica e diferenciação residencial na cidade de Blumenau. Programa de Pós-graduação em Geografia - Unesp de Rio Claro (Dissertação de mestrado): Rio Claro, 1982.

71. SANTOS, Renato Emerson Nascimento dos. “Agendas \& agências: a espacialidade dos movimentos sociais a partir do Pré-Vestibular para Negros e Carentes”. Programa de Pós-graduação em Geografia - UFF (Tese de doutorado): Niterói, 2006.

72. SOUZA, Lorena Francisco de. Corpos Negros Femininos em Movimento: Trajetórias Socioespaciais de Professoras Negras em Escolas Públicas. Programa de Pós-graduação em Geografia - IESA/UFG (Dissertação de mestrado): Goiânia, 2007.

\section{REFERÊNCIAS \\ (identidades e territorialidades negras)}

73. ARAÚJO, Marli Gondim de. A comunidade remanescente de quilombo do engenho Siqueira: conhecimento tradicional e potencialidade da agroecologia na zona da mata pernambucana. Programa de Pós-graduação em Geografia - UFPE (dissertação de mestrado): Pernambuco, 2011.

74. BRANCO, Elaine Regina. Encontros, desencontros e reencontros na trajetória da comunidade remanescente do Quilombo Caçandoca: identidade e territorialidade. Programa de Pós-graduação em Geografia - UNESP-PP (Dissertação de mestrado): São Paulo, 2007

75. CÁCERES, Luz Stella Rodrigues. Territorialidades negras no Brasil e na Colômbia entre a legalidade territorial e a realidade espacial. Programa de Pós-graduação em Geografia - UFRJ (dissertação de mestrado): Rio de Janeiro, 2009.

76. FERREIRO, Simone Raquel Batista Ferreiro. Da fartura a escassez: a agroindustria de celulose e o fim dos territórios comunais no Extremo norte do Espírito Santo. Programa de Pós-graduação em Geografia - USP (dissertação de mestrado): São Paulo, 2002.

77. ___ "Donos do lugar" : a territorialdiade quilombola do Sapê do Norte - ES. Programa de Pós-graduação em Geografia - UFF (Tese de Doutorado): Niterói, 2009 
78. GIACOMINI, Rose Leine Bertaco. Conflito identidade e territorialização. Estado e comunidades remanescentes de quilombos do Vale do Ribeira de Iguape-SP. Programa de Pós-graduação em Geografia - USP (Tese de doutorado): São Paulo, 2010.

79. GOMES, Angela maria da Silva. Rotas e diálogos de saberes da etnobotânica transatlântica negro-africana: Terreiros, quilombos, quintais da grande BH. Programa de Pós-graduação em Geografia - UFMG (tese de doutorado): Minas Gerais, 2009

80. JESUS, Mônica Ramos de. Migração Quilombola: Território e Identidade. Programa de Pós-graduação em Geografia - UNB (dissertação de mestrado): Brasília, 2007

81. LIMA, Gerson Diniz. Agricultura camponesa em territórios quilombolas rurais no Alto do Jequitinhonha-Minas Novas/MG. Programa de Pós-graduação em Geografia - UFMG (Dissertação de mestrado): Minas Gerais, 2006

82. MOREIRA, Alecsandra Pereira da Costa. A luta pela terra e a construção do território remanescente de quilombo de Caiana dos Crioulos, Alagoa Grande - PB. Programa de Pós-graduação em Geografia - UFPB (Dissertação de mestrado): Paraíba, 2007.

83. PAULA, Marise Vicente de. KALUNGA: O Mito do Isolamento Diante da Mobilidade Espacial. Programa de Pós-graduação em Geografia - UFG (Dissertação de mestrado): Goiânia, 2003

84. RATTS, Alecsandro José Prudêncio. Fronteiras invisíveis: territórios negros e indígenas no Ceará. Programa de Pós-graduação em Geografia - USP (Dissertação de mestrado): São Paulo, 1996

85. SANTOS, Janeide Bispo dos. A territorialidade dos quilombos de Irará (BA): Olaria, Tapera e Crioulo. Programa de Pós-graduação em Geografia - UFBA (dissertação de mestrado): Bahia, 2008

86. SANTOS, Maria Priscila Miranda dos. A comunidade de Castainho: uma contribuição aos estudos geográficos de remanescentes de quilombos em Garanhuns. Programa de Pós-graduação em Geografia - UFPE (dissertação de mestrado): Pernambuco, 2010.

87. SILVA, Simone Rezende da. Camburi, território de brancos, negros e índios no limite do concenso caiçara. Transformações de uma população tradicional camponesa. Programa de Pós-graduação em Geografia - USP (dissertação de mestrado): São Paulo, 2004.

88. ___ Negros na mata atlântica, territórios quilombolas e a conservação da natureza. Programa de Pós-graduação em Geografia - USP (Tese de doutorado): São Paulo, 2008.

89. SOUZA Elane Bastos de. Terra, território, quilombo: à luz do povoado de Matinha dos Pretos. Programa de Pós-graduação em Geografia - UFBA(dissertação de mestrado): Bahia, 2010.

90. VELLOSO, Alessandra D`Aqui. Mapeando narrativas : uma análise do processo históricoespacial da Comunidade do Engenho II - Kalunga. Programa de Pós-graduação em Geografia - UNB (dissertação de mestrado): Brasília, 2007. 


\section{REFERÊNCIAS \\ (geopolítica dos países africanos)}

91. BAIA, Alexandre Hilário Monteiro. Os conteúdos da urbanização em Moçambique: considerações a partir da expansão da cidade de Nampula Programa de Pós-graduação em Geografia - USP (tese de doutorado): São Paulo, 2009.

92. BARBOSA, Regina Coeli Zuma Moreira. Espaço e segregação residencial em Harare - Zimbábue: Herança do passado colonial e permanência após a Independência. Programa de Pós-graduação em Geografia - UFRJ (dissertação de mestrado): Rio de Janeiro, 1994.

93. FERNANDES, Mario bastos. Angola: Estado-Nação, Movimentos Sociais e Disputas Territoriais - O Caso da Província de Ngangela. Programa de Pós-graduação em Geografia - UFRJ (dissertação de mestrado): Rio de Janeiro, XX.

94. MARETI, Claudio Carrera. Comunidade, natureza e espaço: gestão territorial comunitária? Arquipélago dos Bijagós, África Ocidental. Programa de Pós-graduação em Geografia - USP (tese de doutorado): São Paulo, 2002

95. PENHA, Eli Alve . Relações Brasil - África e Geopolítica do Atlântico Sul. Programa de Pós-graduação em Geografia - UFRJ (Tese de doutorado): Rio de Janeiro, 1998.

96. SALACHE, Rosane. Determinantes geopolíticos e diplomáticos das relações comerciais entre Brasil e África (1964-2007). Programa de Pós-graduação em Geografia - UEPG (dissertação de mestrado): Ponta Grossa, 2009.

97. SCHUTZER, Herbert. Geopolítica brasileira na África subsaariana: assertivas cooperativas e ou conflitivas dos governos de Geisel (1974-1979) e Lula (2003-2006). Um estudo de geopolítica comparada. Programa de Pós-graduação em Geografia - USP (dissertação de mestrado): São Paulo, 2009

98. SILVA, Armênico Neves da. Dinâmica socio-espacial e produção habitacional na periferia de Maputo-Moçambique a partir da década de 1970: destaques para os bairros Polana Caniço "A" e "B". Programa de Pós-graduação em Geografia - UFSC (Dissertação de mestrado): Santa Catarina, 2011.

99. SORÉ, Yassoungo. O café em São Paulo e na Costa do Marfim. Programa de Pós-Graduação em Geografia - USP (Dissertação de mestrado): São Paulo, 1977.

100. WILKEN, Ronaldo. A Projeção Geopolítica do Brasil na África Lusófona: Ações e Omissões nas Relações com Angola. Programa de Pós-graduação em Geografia - UERJ (dissertação de mestrado): Rio de Janeiro, 2009. 


\section{REFERÊNCIAS \\ (território e lugar nas manifestações culturais negras)}

101. CARNEIRO, Leonardo. A Metrópole Sagrada: Geograficidades Afro-brasileiras no Rio de Janeiro. Programa de Pós-graduação em Geografia - UFF (Tese de doutorado): Niterói, 2009.

102. CORREAA, Aureanice de Mello. Irmandade da Boa Morte como manifestação cultural afro-brasileira: de cultura alternativa à inserção global. PPG-UFRJ (Tese de doutorado): Rio de Janeiro, 2004.

103. DIAS, Jussara Cristina V. R. Territórios do candomblé: a desterritorialização dos terreiros na região metropolitana de Salvador. Programa de Pós-graduação em Geografia - UFBA (Dissertação de mestrado): Salvador, 2003.

104. FERRACINI, Rosemberg Aparecido Lopes. O Espetáculo na Praça: Territorialidade, Identidade e Rituais Negros na Cidade de Goiás. Programa de Pós-graduação em Geografia IESA/UFG (Dissertação de mestrado): Goiânia, 2006.

105. KINN, Marli Graniel. Negros congadeiros e a cidade: costumes e tradiçõesnos lugares e nas redes da congada de Uberlândia-MG. Programa de Pós-graduaçao em Geografia Humana (Dissertação de mestrado): São Paulo, 2006

106. OLIVEIRA, Denilson Araújo de. Territorialidades no mundo globalizado: outras leituras de cidade a partir da cultural Hip Hop na metrópole carioca. Programa de Pós-graduação em Geografia - UFF (Tese de doutorado): Niterói, 2006.

107. PAULA, Marise Vicente de. Sob o manto azul de Nossa Senhora do Rosário: mulheres e identidade de gênero na congada de Catalão (GO). Programa de Pós-graduação em Geografia - IESA/UFG (Tese de doutorado): Goiânia, 2010.

108. RODRIGUES, Ana Paula Costa. Corporeidade, Cultura e Territorialidades Negras: A Congada em Catalão-GO. Programa de Pós-graduação em Geografia - IESA/UFG (Dissertação de mestrado): Goiânia, 2008.

109. SOUSA, Patrícia Pereira Alves de. Corpos em Drama, Lugares em Trama: gênero, negritude e ficção política nos congados de São Benedito (Minas Novas) e São José do Triunfo (Viçosa) - MG. Programa de Pós-Graduação em Geografia - UFMG (Dissertação de mestrado): Belo Horizonte, 2011.

110. TEIXEIRA, José de Paula. Paisagens e territórios religiosos afro-brasileiros no espaço urbano: terreiros de Candomblé em Goiânia. Programa de Pós-graduação em Geografia - IESA/UFG (Dissertação de mestrado): Goiânia, 2009. 